but no power to put it in motion. The accumulation increases so gradually that the cecum distends slowly until the imperfect valve of the appendix is open, and the contents of the cecum press in. Irritation and stimulation is the result producing contraction and expulsion. This irritation and stimulation is communicated to the cecum, and by its contraction the contents are forced up through the colon or elevator, and the depot is emptied and the appendix closes (if no grape seed or any other hard substance becomes entangled in its valve) and remains quiet and in a restful state, until there shall be a siruilar demand made on it, to assist in removing undue accumulations in the cocum in a similar way. This would not be necessary if man did not maintain the upright position, hence no animals have an appendix except those that maintain the upright position, viz., the wombat, orang-outang and man. This is a strong circumstance in favor of the position taken. The appendix like any other organ has a limit to its capacity. If overworked and badly treated, it will break down and fail, and instead of performing its functions it will allow the contents to remain in it, producing inflammation resulting in gangrene, not only being destroyed itself but inviting destruction upon the whole body, upon the principle that a little leaven leaveneth the whole lump. This sacred adage has never been more forcibly illustrated than in the diffusible. ness of a poison germ originating in or developing in the abdominal viscera.

Another potent factor that neutralizes the function of the appendix, is slow bowels or constipation exercising its influence by the damming-back process closing up the elevator or colon, increasing the demand on the appendix beyond its capacity until appendicitis is the result, and once developed it is almost sure to return. And as slow bowels have so alarmingly increased until constipation to a degree is almost the rule or natural condition of a majority of the people this is an easy explanation as to why appendicitis has grown from a very rare affection to one of remarkable frequency. Therefore, it is not true, that it has always existed to the extent that it does now and was overlooked by our illustrious predecessors, for in all other things they proved themselves the equals of the present day of great and glorious workers in medical and scientific research. Man's habits have changed. In fact the man himself has changed. $\mathrm{He}$ once had a large foot and a small head. He used a number ten shoe and a number six hat. $\mathrm{He}$ now wants a number seven shoe and a number eight hat. There is less physical exercise and labor for him. There is more mental worry and work for him. $\mathrm{He}$ does not go to bed and sleep all night as did his fathers. $\mathrm{He}$ does not live on coarse laxative food that required much mastication, developed his teeth and strengthened all his digestive powers. Hence indigestion, constipation and appendicitis were unknown to our ancestors, and would be unknown to us if we had proper food rightly prepared, tuken at proper intervals, in necessary quantities, without hurtful stimulants and narcotics and all other things that have a tendency to retard digestion. Then let us not remove the appendix, but let it remain to perform its God-given function.

Let us relieve it and protect it. Take time to eat and time to sleep and to do everything that is necessary to preserve and protect the body, and so for as this life is concerned all will be well.

\section{PHYSICAL DEVELOPMENT OF WOMEN.}

Presented to the Section on Physiology and Dietetics at the Forty-eighth Annual Meeting of the American Medical Association. held at Philadelphia, Pa., June 1-4, 1897.

BY HARRIET E. GARRISON, M.D. DIXON, ILL.

"Our civilization is hard upon the women," remarked a highly cultivated woman as she sat in my office discussing the way by which she could be restored to her usual vigor. This remark was called forth by my insistence upon the statement that nothing but abso. lute rest would enable the overwrought mind and body to recover their usual tone. The family inheritance of acumen and mental vigor, which had carried a brother to a seat upon the bench of the Supreme Court of our State, had sent the sister into all kinds of philanthropic works. These, and looking well to the ways of her household, had made serious inroads upon a once vigorous constitution.

Our civilization is hard upon women only because they are in a state of transition from the wholly material to the entirely intellectual. When all that was required of woman's brain was to read a little and write sufficient to keep up a limited correspondence, she had strength and energy sufficient to develop into a healthy, hearty housewife and mother. But now our school system demands that every girl, whatever her after-life is to be, must have brains developed sufficiently to write a book, without regard to the effect this may have upon her physical development. And every woman must engage in some kind of benevolent work no matter if she is starving for outdoor exercise, fresh air and sunshine.

Is there much inherent difference between the physical capacity of the sexes? A study of the agricultural laboring classes leads me to think that woman can be trained to as much physical endurance as man. Among the foreign peasants the women work side by side in the fields with their husbands and brothers, usually doing the more laborious part of the work. It is the woman of Germany, who, hitched side by side with her faithful cow draws the plow, while the man takes the less muscular but more intellectual task of guiding it. While on a visit to "the great red pipestone quarry" of Minnesota, as a tribe of indians were taking out their supply of pipe-stone, I noticed that the men cut the stone from the quarry but the women were out along the railroad track splitting discarded ties into fire-wood, and as we drove back to the town we marveled to see the immense load of wood fastened upon the back of each squaw as she returned to the camp. Among our own agriculturists I have been surprised at the amount of endurance displayed by the women. In one case a woman, the mother of four young children, after pitching hay upon the wagon all day endured the pangs of labor all night and called me in the morning; but the fetus had not yet reached maturity and $I$ advised rest in bed after a quieting potion. But as soon as the pains were relieved she got out of bed and did the family washing and then went back into the hay field until the fetus matured, when she was delivered without the aid of an obstetrician. Again I was summoned in haste to find her kneeling beside her bed with the livid face and gasping breath of the extreme anguish of angina pectoris. Hot applications, morphia and heart stimulants soon brought relief and then I found that she was within four weeks of her ninth accouchment. Besides her usual house and field-work she had been milking six- 
teen cows night and morning. In two days after I saw her she went back to her usual work and in two weeks after her delivery she returned to her place in the dairy. Nor is this an isolated case; there are hundreds of women who enjoy such work.

But these cases are in marked contrast to those we meet among our intellectual women who are semior whole invalids from early childhood to the grave. Some of these are born invalids, inheriting neurosis from neurotic ancestors; others have invalidism thrust upon them. While we do not care to have our women become farm laborers, we would like to have them with sufficient physical endurance to do the work, both physical and intellectual, which falls to their share without that constant tired feeling of which so many of them are continually complaining.

I think the late Dr. Frank Hamilton gave us the key to the lack of physical development in our women when he wrote: "Calisthenics may be very genteel and romping very ungenteel, but one is the shadow, the other the substance of healthful exercise. Girls need health as much, nay, more than boys. They can only obtain it as boys do by running, tumbling, by all sorts of innocent vagrancy. At least once a day girls should have their halters taken off, the bars let down and be turned loose like young colts."

If our girls were turned loose to amuse themselves spontaneously, to run up hill and roll down, to skip and jump without rhyme or reason, except as it is supplied by the exuberance of their own innocent natures, there would be less headache in adult life. Only the other day an earnest, conscientious mother asked me about her little girl of seven, whether I thought it just right for her to allow her to romp on the floor with her little baby sister. As the mother expressed the matter, the girl had grown so rapidly she looked very ungainly rolling over' the floor. "So much the more need for her to roll on the floor or grass that she may grow in strength and beauty," was the advice I gave the mother. In the tall, rapidly growing girl there is not sufficient nutriment supplied to the muscles to support the trunk in the erect attitude of standing, and rolling gives exercise to various sets of muscles without overtaxing them in trying to support the trunk. Many of our girls with round shoulders and rickety spines would have been saved these deformities had they done more rolling. A few weeks ago I had under my charge a girl of 12 years who was round-shouldered and small looking. She was very sick with la grippe and developed dangerous heart symptoms, for which I confined her in the re cumbent posture for two weeks. When I finally allowed her to leave her bed, her mother was astonished at her great increase in height and declared she had grown four inches while in bed. I did not suppose there had been any actual gain as she had not taken sufficient nourishment, in fact she had lost in weight and the increase in height was due to the muscles having become rested and strong enough to liold the body in perfect shape. I advised the mother to have the girl spend half the time in bed until the muscles became more fully developed.

Fresh air, fresh water and sunshine should be the inalienable right of every child in this land of the free and home of the brave, but our women are starving for these very things. Not only are the girls from the sweat-shops and factories, who are shut in for ten or twelve hours where no sunshine or fresh air can reach them, crying Hood's refrain,

\author{
"It's $O$, to be a slave, \\ Along with the barbarous Turk, \\ Where woman has ne'er a soul to save, \\ If this is Christian work,"
}

but the woman of social position must give at least ten hours daily to her duties, shut in as closely from fresh air and sunshine as her humble sister.

Our school authorities do not recognize the need of fresh air and exercise in the sunshine, with plenty of fresh water, but year after year try to drill into starved brains knowledge, a greater part of which is of no practical benefit to that particular individual. If the State wishes to educate the children let it make the education common. As the schools now stand the privilege is extended to but a small fraction of the children, and these are the ones who least need the State's help. Let our school curriculum be made broad enough to include development of body as well as mind; let the schoolhouses be set away from other buildings with large, surrounding playgrounds. It is not necessary for the schoolhouse to be placed at the door of the scholar's home, but let there be public conveyances to carry the scholars to the door of the schoolhouse.

Nothing which the municipality could do would elevate Mott Street in New York more than for the children to be gathered up every day and carried a few miles into the country by an electric line to a pleasant school building with a ten-acre playground arranged as a park, with hills to climb and valleys to explore, and grounds for all games; with bath-houses and swimming pools, where once a week every child is made to plunge and taught to swim. This can be done with no more expense than our present school system. It may be necessary to shorten the time in which the scholar is the ward of the State, and our sweet girl graduates with their beautiful ribbons, laces and fluffs, with their tired, drawn faces which even "opalin" will not make young and fresh, may disappear, but in their places will come the fresh glad girls, able with their strong, healthy, young bodies to fill every sphere.

With this change must come other changes. OuI civic authorities must take cognizance of the physical needs of our girls and provide places, with every facility for reaching them, where girls are incited to healthy exercise with basket-ball and other hardy games. The State levies a tax for free libraries where the girls may be shut in with foul air and with literature as detrimental to their minds as the air is to their bodies. If any one doubts this statement let them look over the list of books most called for in our public libraries. We do not want to banish all public libraries, though there is a class of books which should be banished, but with these supply play places with games and bathing facilities, where every girl can engage in the healthy exercise of swimming. The plea is sometimes urged that bacterial disease is transmitted in free bathing establishments, and so is every book used in a free library covered with germs; and more dangerous germs as they are gathered from the homes of diphtheria and typhus fever. If the water is frequently changed in the bathing pools the danger of contagion is reduced to an infinitesmal quantity. In communities where there are clear running streams there are hundreds of women who never have a plungebath from the cradle to the grave; from birth to burial they never know the cleansing which only submersion in clear, pure water can give. Here the fastidiousness 
of the community prevents the bountiful provisions of nature for woman's physical needs from being utilized; and even boys are fined for yielding to tempta. tion of the pure sweet influence of the running water anywhere within telescopic view of the over-nice passer.by. Verily, those who do not bathe should pay the fines, as the crimes of the community are perpetrated by the great unwashed. To be unwashed for a week should be a crime. Every community too large or cultivated to use primitive bathing methods should provide free bathing facilities within its borders, and the women of the community should be urged to make use of these unless they have private arrangements for plunge-baths. Nature has clearly indicated that to be thoroughly cleansed the body must be submerged in water, even the ears which so many fill with cotton before a plunge will be none the worse for being washed out with pure water.

Let every physician assist in enforcing the law for shorter working hours for women, and urge that their free hours be spent in healthful outdoor exercise, and we will have a brighter, healthier, happier set of women.

\section{A CASE OF VICARIOUS MENSTRUATION FROM THE LUNGS.}

BY T. L. CHADBOURNE, B.S., M.D. COLUMrUs, онто.

Cases of vicarious menstruation are not rare, but cases of long-standing vicarious bleeding from the lungs are tolerably uncommon.

On consulting the literature one is struck by the small number of such cases that have been reported in this country.

The Index Medicus from 1888 to June, 1896, has only about twenty-five distinct references, the American Journal of Obstetries from 1886 less than ten, and the American Journal of the Medical Sciences for the same time has but one case indexed.

The chief interest of these cases lies in their connection with the question of tuberculosis. Some of them are mistaken for phthisis, while many of them really are tuberculosis, and only later develop the signs of the disease.

Thomas ${ }^{1}$ reports a case of a patient, age 40 years, who, after twenty years of normal menstrual life, slowly began to have hemorrhages from the lungs. She lost weight greatly and had every appearance of pulmonary phthisis. Physical examination showed no signs in the lungs, but disclosed an occluded cervical canal. After operation the patient recovered entirely in six weeks.

Ford" reports a case of a patient aged 25 years, who menstruated at 15 , at 19 took cold and ever since has had pulmonary hemorrhage for three or four days every month; has not lost weight.

Stuart ${ }^{3}$ calls attention to a patient with the follow. ing history: Age 15 years; menstruated at 14; tuberculous family history.

The patient suddenly began to have vomiting of blood with occasional hemoptysis. After seven months she developed signs of tuberculosis and a few months later died of this disease.

Stuart calls attention to the fact that, from the first, the case was thought to be tuberculous, although for seven months no signs could be made out.

1 Amer. Jour. Obst., XIX.

3 Journal American Medical Association, Ix.
Kober ${ }^{4}$ gives a very interesting case as follows: Age 18 years and 9 months; has never been ill; menstruated for two years.

February 10 she had a slight period and marked hemoptysis; was very sick at stomach. At this time she developed a mild pneumonia behind, below, which resolved in ten days.

March 4, again hemorrhage, nausea and pneumonia. Soon after this, catarrh of the right apex. A third time she had hemorrhage, with other symptoms as before. She died in June, of tuberculosis.

The hemoptysis came on at a time when no suspicion of pulmonary disease could exist, and the author insists that the prognosis in cases of recurring hemoptysis must be very guarded.

May 8, 1896, there came to the Michigan University Hospital a patient for examination of her lungs, as she was thought to have consumption.

The patient gave the following history: Age 18 years, menstruated at 14 ; one sister dead of spinal disease; no history of lung trouble. The patient has generally been well; three years ago had typhoid; says she has had slight hacking since. For the last year, slight yollowish expectoration, never bloody except as stated below.

Since her eighth year she has had enlarged glands in the neck. These have varied in size, have never suppurated. Have once or twice been favorably influenced by iodin.

Fifteen months ago she took cold, and the next afternoon, during a severe coughing fit, suddenly began to spit blood, which came up rapidly; for the most part rather thick, although some of it was frothy; quantity sufficient to saturate two or three handkerchiefs. Her period was due at this time. Regular flow did not occur, but she continued to spit blood for four days. She missed her next three menstrual periods, but at the times these were due she spat blood, although never so much as at first.

The regular flow then reappeared and was normal for four months, during which time there was no hemoptysis. During the five next succeeding months the hemoptysis again replaced the catamenia. During the last three months the flow has occurred in the normal manner.

The bleeding has usually occurred just at the time of the catamenia, although in one instance last winter it was delayed about a week.

With the hemorrhage she has pain in the chest and a good deal of nausea, both before and afterward. There is no disturbance of the stomach at other times.

She has slight bearing down pains during the first part of her period. The flow is scanty and she is slightly irregular, usually postponing.

Physical examination at this time showed, aside from the enlarged glands in the neck, no anomaly, the lungs being entirely negative.

May 27, she entered the hospital and, during a stay of a week, was several times examined and the following notes were made: Patient undersized; muscles in fair condition; tongue large, with thin white coating; on both sides of neck enlarged glands, varying in size from a walnut to a pea; glands in left axilla also slightly enlarged; they are elastic, not tender, not adherent; skin not reddened. Thorax long, narrow, especially below; of moderate depth; epigastric angle narrow. Lying, supraclavicular spaces are symmetric. Expansion slight but symmetric. Palpation is negative.

Percussion : Good resonance over apices and clavicles, slightly fuller left than right. Further percussion yields good resonance everywhere.

Auscultation: Normal vesicular over both apices; slightly interrupted vesicular under clavicles on both sides; normal vesicular elsewhere; no adventitious sounds.

Heart negative.

Genital tract examined by Professor Martin, who found, aside from a rather small uterus, no abnormity.

Further physical examination negative.

Urine: Small amount, negative.

Blood : Covers show some variation in the size of the erythrocytes; leucocytes 4,200 ; reds, 4,446,000; hemoglobin (Gowers) 70 per cent.

Although she remained in the hospital a week, no sputum could be obtained.

4 Berl. Klín. Wochenschr., 1895 